\title{
CORRECTION
}

\section{Correction to: Correct-by-construction model-based design of reactive streaming software for multi-core embedded systems}

\author{
Fotios Gioulekas ${ }^{1} \cdot$ Peter Poplavko ${ }^{2} \cdot$ Panagiotis Katsaros $^{1} \cdot$ Saddek Bensalem $^{3} \cdot$ Pedro Palomo $^{4}$
}

Published online: 12 July 2019

○) Springer-Verlag GmbH Germany, part of Springer Nature 2019

\section{Correction to: International Journal on Software Tools for Technology Transfer \\ https://doi.org/10.1007/s10009-019-00521-7}

Updated Fig. 7 ( $p_{i}$ is the job's process, $k_{i}$ is the job's invocation count, $A_{i}$ is the invocation time, $D_{i}$ is the absolute deadline and $C_{i}$ is the WCET).

Publisher's Note Springer Nature remains neutral with regard to jurisdictional claims in published maps and institutional affiliations.

The original article can be found online at https://doi.org/10.1007/ s10009-019-00521-7.

Fotios Gioulekas

gioulekas@csd.auth.gr

Peter Poplavko

petro.poplavko@siemens.com

Panagiotis Katsaros

katsaros@csd.auth.gr

Saddek Bensalem

Saddek.Bensalem@univ-grenoble-alpes.fr

Pedro Palomo

pedro.palomo@deimos-space.com

1 Department of Informatics, Aristotle University of Thessaloniki, Thessaloniki, Greece

2 Mentor ${ }^{\circledR}$. A Siemens Business, Montbonnot, France

3 VERIMAG, Université Grenoble Alpes (UGA), Grenoble, France

4 Deimos-Space $®$, Madrid, Spain 
Fig. 7 The Task Graph generated for the FPPN network example shown in Fig. 3

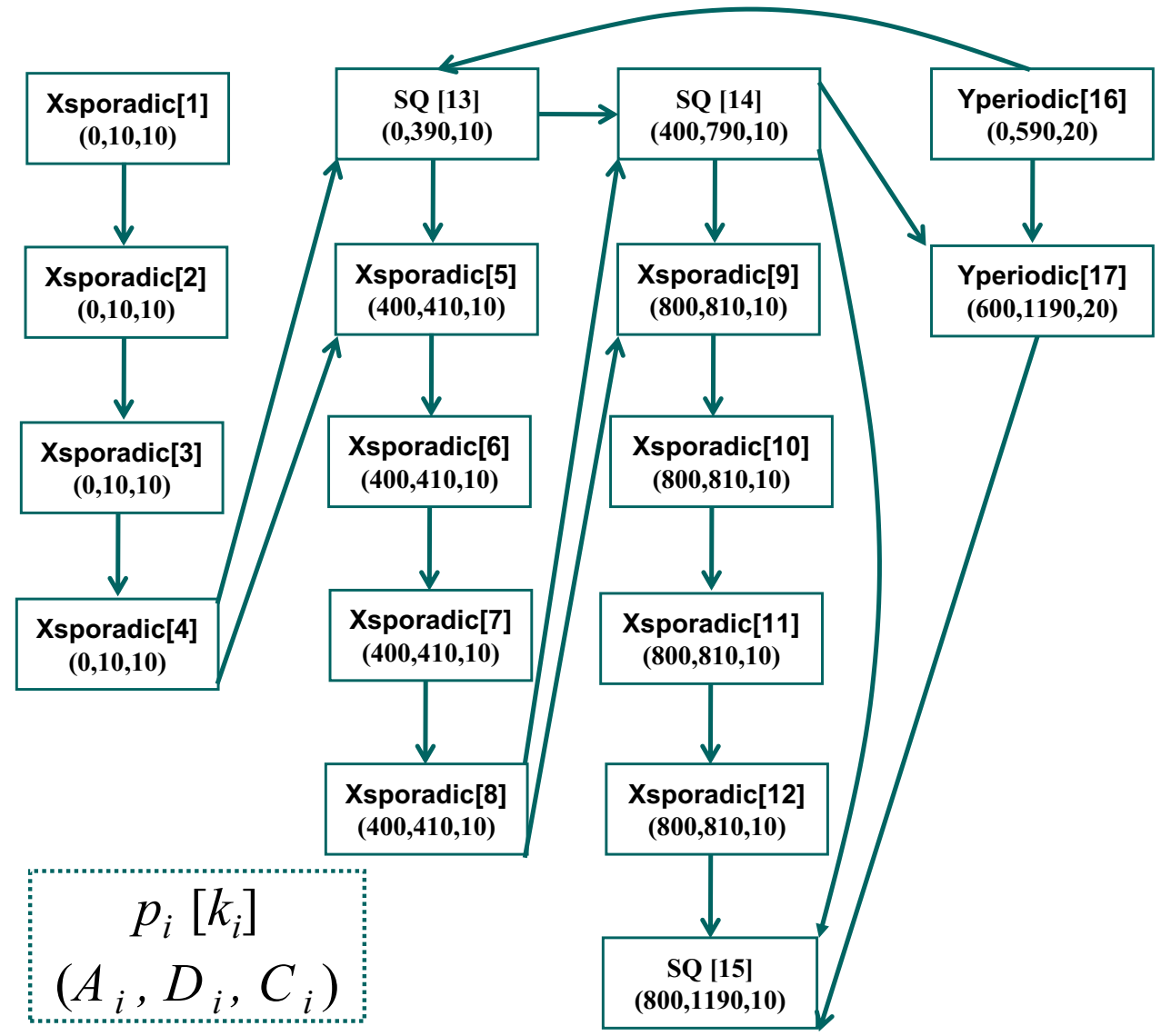

